\title{
SINDICATO, CRISE ECONÔMICA E ESTRATÉGIAS REGIONAIS novas dimensões da participação política no ABC Paulista ${ }^{1}$
}

\author{
JoséRicardoRamalho* \\ Iram JácomeRodrigues"
}

\begin{abstract}
A proposta do artigo é discutir, a partir do caso do ABC paulista, as estratégias sindicais criadas em contextos de crise econômica, e analisar os mecanismos de mobilização acionados para propor alternativas político-institucionais em âmbito regional, com o objetivo de proteger e estimular a criação de empregos e enfrentar os efeitos sociais das demissões de trabalhadores. A hipótese principal é a de que a ação de sindicatos com tradição de luta trabalhista, densidade institucional e acúmulo político regional e nacional, com canais de interlocução ativos com governos municipais, estaduais e nacionais e com poder de mobilização de suas categorias, acabam por desempenhar um papel decisivo e, de certa forma, inovador, na formulação de novos mecanismos institucionais para discutir estratégias políticas de enfrentamento das dificuldades impostas às regiões e localidades, passando a exercer influência nas novas concepções construídas em situações de crise econômica regional.

PALAVRAS-CHAVE: crise econốmica, sindicato, territórios produtivos, região do ABC-Brasil
\end{abstract}

A proposta do texto é analisar a consolidação de estratégias sindicais criadas em contextos de crise econômica e os mecanismos de mobilização institucional acionados pelas organizações dos trabalhadores com vistas a influenciar os debates sobre políticas de desenvolvimento regional e local, bem como os mecanismos de estímulo a novas atividades econômicas e criação de empregos. Vamos tomar como exemplo o ABC paulista no contexto

${ }^{1}$ Este artigo é uma versão modificada do texto apresentado no GT Trabalho e Sindicato na Sociedade Contemporânea durante o $33^{\circ}$ Encontro Anual da ANPOCS em outubro de 2009. Beneficia-se de parte dos resultados de pesquisas que vêm sendo desenvolvidas pelos autores: "Trabalho, distritos industriais e novas estratégias de desenvolvimento regional" e "Trabalho, sindicato e desenvolvimento regional: estudo comparativo entre as regiões do ABC Paulista e o Sul Fluminense”, que contam com o apoio do CNPq e da Faperj (Programa Cientistas do Nosso Estado e Pensa Rio). Somos gratos aos colegas do GT da ANPOCS que fizeram comentários e sugestões ao texto.

* Doutor em Ciência Política pela Universidade de São Paulo. Professor do Programa de Pós-Graduação em Sociologia e Antropologia da Universidade Federal do Rio Janeiro (UFRJ).

Largo de São Francisco 1 - sala 418 - Centro. Cep: 20051070 - Rio de Janeiro, RJ - Brasil. jricardoramalho@uol.com.br

**Doutor em Sociologia pela Universidade de São Paulo. Professor do Departamento de Economia e do Programa de Pós-Graduação em Sociologia da Universidade de São Paulo (USP). ijrodrig@usp.br das duas últimas décadas, pelo fato de essa região: a) ter enfrentado uma crise econômica nos anos 1990, relacionada com o processo de reestruturação produtiva das empresas globais e de suas cadeias produtivas, resultando no fechamento de fábricas, no aumento do desemprego e no deslocamento de investimentos produtivos para outras localidades (Conceição, 2008; Rodrigues; Ramalho, 2007); b) ter enfrentado uma crise financeira mundial de grandes proporções em setembro de 2008, que resultou em redução das atividades industriais (principalmente no setor automotivo), e no aumento do desemprego; e c) ter sindicatos com tradição histórica de luta trabalhista e de mobilização política, densidade institucional e acúmulo político regional e nacional, o que inclui canais de interlocução com governos municipais, estaduais e nacionais. A observação das práticas sindicais no $\mathrm{ABC}$ ao longo desse período histórico, a nosso ver, permite também uma discussão sobre dinâmicas de desenvolvimento territorial no contexto da globalização e a formulação de novas relações sociais entre atores com interesses e posições econômicas e políticas diversas e divergentes. Isso abri- 
ria a possibilidade de investigar se, nessa situação social (de crise), poderiam ser criadas condições necessárias à emergência de atividades capazes de incorporar setores da população à esfera da cidadania, dando conotação política ao universo produtivo (Cocco et al, 1999); ou se seria viável o estabelecimento de uma nova ordem econômica regional, na qual haja "um domínio coletivo de exterioridades (...), que deve ser gerenciado por instituições públicas" (Scott, 1999, p.30-31); ou se, ainda, a população de uma cidade poderia ser considerada como protagonista de desenvolvimento local e político, o que requereria uma visão estratégica do novo papel das cidades no cenário internacional (Klink, 2003).

Esse complexo processo de construção institucional ocorrido nas duas últimas décadas foi marcado por dificuldades e conflitos inerentes a novas experiências que envolvem atores com diferentes interesses, como empresas, administração pública, organizações da sociedade civil e trabalhadores. Sem desconsiderar os percalços dessa conjuntura, nossa intenção é ressaltar, no caso do ABC, sob o impacto das crises, a construção, mesmo que imperfeita, de um modelo de desenvolvimento territorial que não prescinde do apoio estatal (municipal, estadual e federal) e que apresenta características específicas de participação e ação pública dos seus principais grupos sociais, certamente relacionadas com o legado histórico da mais desenvolvida aglomeração industrial do país. Nesse contexto, podem ser observadas algumas iniciativas de coordenação política, erguidas com razoável consenso entre os atores locais, que incluem os representantes dos trabalhadores e resultam em estratégias públicas de recuperação econômica regional.

\section{POSIÇÕES TEÓRICAS}

As considerações que estamos propondo podem ser desenvolvidas com diferentes ênfases e pontos de vista. Não é novidade, por exemplo, que o sindicato dos metalúrgicos do $\mathrm{ABC}$ e outros sindicatos da região já vêm defendendo, há pelo menos duas décadas, uma postura sindical proativa, no sentido de preservar atividades econômicas e empregos como forma de enfrentar as dificuldades criadas pelo desemprego, a "precarização" das relações de trabalho e a terceirização das atividades industriais. Esse tipo de opção cria a necessidade, no quadro do atual processo de globalização, de inclusão das questões relativas ao desenvolvimento regional e local na discussão sobre novas estratégias sindicais.

Um modo de tratar essas questões é através do debate sobre os mecanismos de coordenação local e regional criados no novo contexto do padrão industrial flexível e que se desenvolveram na literatura acadêmica mediante o uso do termo "governança". As formulações de Guimarães e Martin (2001) sobre esse tema são esclarecedoras, principalmente quando identificam na "coordenação" "entre atores independentes", para "lidar com as questões da ação coletiva e da cooperação", uma abertura para avaliar de modo mais complexo as novas práticas "e representações que se difundem em torno da noção de 'flexibilidade". Esses autores chamam a atenção também para o surgimento de instituições e espaços públicos, nesse novo contexto industrial, que, mesmo informalmente, "articulam atores sociais e políticos com vistas a enfrentar desafios postos pelo processo de intensificação da integração produtiva em âmbito global".

Na confluência de várias vertentes de leitura sobre processos de desenvolvimento (regional), cremos ser possível dialogar com um conjunto de concepções presentes em outras disciplinas, especialmente a geografia e a economia, que vêm reformulando suas concepções de "território" ou de "desenvolvimento territorial", de modo a refletir sobre o papel dos trabalhadores nos processos de transformação pelas quais passaram localidades e aglomerados industriais.

Ao referir-se à participação dos agentes sociais na discussão sobre novas estratégias de desenvolvimento econômico e territorial no atual contexto da globalização, Storper (1999), por exemplo, reforça uma linha de interpretação que nos parece bastante pertinente para analisar a experi- 
ência do ABC. Ele considera que o funcionamento do desenvolvimento regional deve complementarse com a possibilidade de pensar a

economia como relações, o processo econômico como conversação e coordenação, os agentes do processo não como fatores, mas como atores humanos reflexivos, tanto individual como coletivamente, e a natureza da economia de acumulação não só como benefícios materiais, mas como ativos relacionais (Storper, 1999).

No mesmo sentido vai Pecqueur (2005), ao abordar a questão do "desenvolvimento territorial" diante das mudanças na economia internacional. Para ele, esse tipo de desenvolvimento "não pode ser implantado por decreto; permanece uma construção dos atores, mesmo que políticas públicas apropriadas possam estimular e mobilizar esses atores". Também Pires e Verdi (2007) enfatizam a importância de pensar o território

... em termos de espaços socialmente criados e organizados pelos atores sociais, a partir dos seus ativos e recursos, como condições e capacidades para materializar inovações técnicas e sociais, além de gerar sinergias positivas entre os responsáveis pelas atividades produtivas (tecido empresarial) e a comunidade (tecido cidadão).

Essa argumentação aplicada ao Brasil permite identificar mudanças nos chamados "processos de territorialização". Pires e Neder (2005), por exemplo, reconhecem que "a constituição brasileira de 1988 impulsionou novos processos (...) e localizações das atividades econômicas e de desenvolvimento local e regional, abrindo o leque de possibilidades de governanças territoriais". Essa linha de raciocínio ajuda a entender o caso do $\mathrm{ABC}$, e as considerações sobre territórios locais servem como balizamento para explicar os fenômenos que levam a uma articulação política e econômica em situações de crise.

O território local não é o lugar de uma simples projeção do modo de regulação - por exemplo, tal como é definido por instâncias centrais do estado nacional ou de corporações empresariais sobre um espaço geográfico supostamente dado. (Pires e Neder 2005).

Para eles, ao contrário, o território local é uma construção social que gera um sistema de representações comuns aos seus membros, que cria suas próprias regras e que faz emergir as formas de regulação parcial relativamente autônoma por meio de dispositivos territoriais de regulação (Ibidem).

A incorporação de elementos teóricos do debate sobre "distritos industriais" também se justifica no caso do ABC. A discussão mais geral está relacionada à crise do fordismo e o aparecimento de um novo paradigma baseado na cooperação entre pequenas e médias empresas (Terceira Itália). No caso do ABC, pode-se observar a possibilidade ou não de replicação desse paradigma e a criação de uma dinâmica de cooperação entre pequenas e médias empresas em um contexto industrial, com a presença e a hegemonia de uma lógica empresarial de grandes empresas, entidades sindicais fortes e administração pública ativa na busca de alternativas econômicas.

Um retorno rápido à discussão sobre o modelo de distritos industriais mostra que, no caso do $\mathrm{ABC}$, essas considerações auxiliam a entender a construção de novas dinâmicas territoriais. Sengemberger e Pike (1999), por exemplo, valorizam essa perspectiva como "uma abordagem nova e dinâmica do desenvolvimento econômico regional", e afirmam que, no caso paradigmático da Terceira Itália, o "êxito econômico" teria decorrido "não tanto do acesso vantajoso a fatores de produção a um custo baixo - mão-de-obra, terra ou capital baratos -, mas, sobretudo, de uma organização social e econômica eficaz, baseada em pequenas empresas". Para esses autores, "a criação e a expansão das pequenas empresas constituem uma reação ao declínio econômico repentino". E funcionam como um "amortecedor de choques" no ciclo econômico. Sengemberger ePike (1999) também associamà construção desse modelo a mudança no perfil organizacional das grandes empresas. "Em grande medida, esse crescimento [das pequenas empresas] resultou de políticas de descentralização, transferência e desintegração iniciadas em grandes empresas durante a década de 1970".

Outro aspecto é a promoção de clusters como 
política de desenvolvimento regional e local, os quais vêm sendo adotados nos contextos de crise no ABC. Segundo Meyer-Stamer (2001), a promoção de clusters tem como ponto de partida "a observação de que [...] oferece grande potencial para a criação de vantagens competitivas", ou "vantagens de localização". Mas o autor reconhece que, além das "vantagens passivas", podem ser criadas "vantagens ativas", pela ação coletiva ou governamental: uma escola técnica, um laboratório de testes de material e certificação, uma agência de informações sobre comércio exterior etc.

Em suma, toda essa argumentação teórica, utilizada como instrumento para uma reflexão sobre o caso do ABC em conjunturas de crise, pode ajudar a refinar a interpretação sobre as novas práticas de ação sindical e as novas formas de institucionalização do debate econômico e político regional e local, que envolvem mecanismos diferenciados de representação de interesses, de resolução de conflitos e de busca de consensos.

\section{OS SINDICATOS DO ABC E A CRISE DOS ANOS 1990}

A história de combatividade e de protagonismo político na sociedade brasileira das últimas décadas fez do sindicalismo (principalmente metalúrgico) do ABC um reconhecido defensor dos interesses dos trabalhadores, particularmente em relação à manutenção do emprego. A reestruturação das atividades produtivas e a crise econômica dos anos 1990 colocaram os sindicatos na defensiva, tendo em vista o aumento do desemprego e o "enxugamento" e (ou) deslocamento geográfico das unidades fabris. E o distrito industrial da região do $\mathrm{ABC}$, considerado símbolo da modernidade, passou a ser apontado pelo empresariado como "o lugar do atraso" e das ineficiências geradas pelo antigo modelo de industrialização. Foi como resposta ao questionamento de sua vocação produtiva que se criou, no início da década, a Câmara Setorial da Indústria Automobilística. Essa experiência de negociação tripartite (sindicatos, empresas e governo) teve um caráter inovador em termos de relações de trabalho e de elaboração de política industrial, exercitou um mecanismo democrático de gestão pública setorial e representou um aprendizado em novos moldes para os atores sociais da região. ${ }^{2}$

A reação à crise econômica regional alternou entre a busca de novas saídas coletivas e institucionalizadas para a resolução dos problemas e o uso do cálculo econômico puro e simples para, aproveitando o momento de fragilidade dos setores ligados ao trabalho, flexibilizar os vínculos de emprego e justificar o deslocamento para localidades que oferecessem "melhores condições". Na ocasião, a visão sindical interpretou que o fechamento de fábricas, a transferência de unidades fabris e a perda de empregos não podia ser uma decisão restrita ao empresário (Ramalho; Rodrigues; Conceição, 2009). As entidades alegavam a necessidade de o sindicato e o poder público influirem antes (de modo preventivo) e depois (de modo a reduzir os impactos negativos) da decisão do fechamento, assim como cobrar compromissos das empresas com a região. Um exemplo dessa formulação aparece em artigo publicado na imprensa, pelo então presidente do sindicato dos metalúrgicos, Luiz Marinho (2001), que resumiu a forma como os trabalhadores e o sindicato dos metalúrgicos encaravam uma decisão de fechamento de fábrica ocorrida no $\mathrm{ABC}$ :

Além dos aspectos estritamente financeiros [per-
da de salários, impostos, demanda para os forne-
cedores locais], uma fábrica é também o símbo-
lo de um acúmulo tecnológico, de um 'saber fa-
zer' a respeito da produção de um determinado
produto. Em cada funcionário, em cada departa-
mento, em cada norma escrita estão incorpora-
dos, em realidade, vários anos de conhecimentos
- que não se reproduzem com o mero desloca-
mento da fábrica para outra localidade. E vai se
esvair também um know how acumulado pelos
fornecedores (...). Uma série de empresas acaba
sendo afetada. Portanto, quando uma empresa
do porte da (...) decide pela desativação de uma
fábrica, ela não está tomando uma decisão que
diz respeito uniçamente aos interesses privados
da companhia. É toda uma comunidade pública

2 Sobre esse tema, ver Arbix, 1996 e 1997; Oliveira, 1992 e 1993; Diniz, 1993; Cardoso; Comin, 1995 e Cardoso, 1999; Bresciani; Benites Filho, 1995; Anderson, 1999; Silva, 1997; Franco, 1992 e 1993. 
e privada que está envolvida (...). Se a empresa tem o ‘direito’ de estabelecer a estratégia de produção e mercado que considere a mais adequada para si, a sociedade tem o direito também de preservar o que de fato é seu patrimônio: as relações sociais, econômicas e tecnológicas que giram em torno de uma (...) fábrica...

A região do $\mathrm{ABC}$ foi a que mais sofreu com a reestruturação industrial, embora esse processo desencadeasse um conjunto de iniciativas inéditas de gestão pública, com a participação ativa dos principais atores sociais, como foi o caso da Câmara Regional do ABC. A realização dessa experiência se beneficiou de outros fóruns criados anteriormente na própria região, como, por exemplo, o Consórcio Intermunicipal do ABC, que surgiu em 1990 com sete prefeituras, com o objetivo de discutir, planejar e agir de modo integrado nos temas de interesse comum (Daniel, 2001a; Abrucio; Soares, 2001; Reis, 2005; http://www.consorcioabc.org.br). O Consórcio ganhou força política a partir dos novos prefeitos eleitos em 1988, preocupados em dar novas respostas a antigos problemas da região. Naquelas eleições, o Partido dos Trabalhadores (PT), cujas origens estão ligadas à própria ação operária no ABC e que desde o início lutou por mudanças na forma de funcionamento do Estado e de suas instituições, elegeria três dos sete prefeitos. Desse grupo veio também a principal liderança do Consórcio, o prefeito de Santo André, Celso Daniel, defensor dos novos formatos de gestão pública baseados na cooperação para a elaboração de políticas integradas de desenvolvimento local (Daniel, 1995, 1996, 2001a, 2001b; Daniel; Somekh, 1999).

Outro movimento importante para compor esse quadro de transformações regionais foi a criação do Fórum da Cidadania do Grande ABC, em 1994, por iniciativa de setores da sociedade civil. Em um primeiro momento, o Fórum esteve associado ao movimento "vote no Grande ABC" (Petrolli, 2000; Horta, 2003), cujo objetivo era ampliar a representação política regional nas eleições legislativas estaduais e federais realizadas naquele ano. ${ }^{3}$ Após as eleições, as entidades participantes

${ }^{3}$ Nas eleições de 1994, a Região do ABC elegeu 5 deputados federais e 8 deputados estaduais, a maior representação parlamentar de sua história. desse movimento, apoiadas por outras entidades da sociedade civil, decidiram por sua institucionalização, quando o Fórum chegou a congregar cerca de 80 entidades dos mais diversos segmentos (associações empresariais da indústria e do comércio, sindicatos de trabalhadores, representações da mídia local, organizações não-governamentais etc), articuladas em grupos temáticos, para produzir subsídios com vistas a solucionar os problemas regionais. O Fórum parece ter representado um avanço no diálogo e na busca de consensos entre os atores sociais e outro preâmbulo do que viria depois, embora não tenha se confirmado como um espaço efetivo de resolução das questões trazidas pela crise dos anos 1990.

A consolidação de um espaço da negociação regional ocorreu com a criação da Câmara Regional do ABC em 1997, ${ }^{4}$ que se diferenciou do Consórcio Intermunicipal e do Fórum da Cidadania, pela tentativa de integrar os atores públicos e da sociedade civil em uma mesma mesa de discussões. Uma das mais importantes realizações da Câmara Regional foi a implantação, em 1998, da Agência de Desenvolvimento Econômico do Grande ABC. A Agência, uma instituição não-governamental sem fins lucrativos, foi instalada com a missão de dar suporte institucional aos acordos debatidos dentro da Câmara Regional. ${ }^{5}$ A composição do capital da Agência expressa sua natureza mista, não-estatal: 51\% das cotas relativas aos cus-

${ }^{4}$ Os componentes da Câmara Regional do ABC, na segunda metade da década de 1990, foram: o Governo do Estado de São Paulo, o Consórcio Intermunicipal (sete Prefeituras), os Legislativos Municipais, os Parlamentares do ABC na Assembleia Legislativa e no Congresso Nacional, o Fórum da Cidadania, as Associações Empresariais e os Sindicatos de Trabalhadores. Sobre a experiência da Câmara Regional do ABC, ver Daniel; Somekh, 1999 e 2001; Gomes, 1999; Leite, 1999; Guimarães, Comim; Leite, 2001; Boniface, 2001; Klink, 2000 e 2001; Albuquerque, 2001; Câmara Regional do ABC, 2000a e 2000b; Camargo, 2003; e Bresciani, 2004.

${ }^{5}$ A Agência tem como sócios: o Consórcio Intermunicipal; as quatro diretorias regionais do Centro de Indústrias do Estado de São Paulo (CIESP); as Associações Comerciais e Industriais dos sete Municípios; os Sindicatos de Trabalhadores (Sindicato dos Metalúrgicos do ABC, Sindicato dos Químicos do ABC, Sindicato das Costureiras, Sindicato da Construção Civil); o Serviço de Apoio às Micro e Pequenas Empresas (SEBRAE), as empresas do polo petroquímico regional (Petroquímica União, Solvay, Cabot, Polietilenos União, Polibrasil, Crevron, Oxicap e Petrobras) e as universidades (IMES, UNI-A, Fundação Santo André, UNIBAN, UNIABC, Metodista, FOCO). 
tos da instituição referem-se à sociedade civil e 49\%, aos municípios, por meio do Consórcio Intermunicipal do Grande ABC.

Avaliações mais recentes sobre essas novas experiências institucionais remetem ao debate teórico a respeito de novas práticas políticas em territórios reconvertidos pelas exigências e mudanças no processo de acumulação e no padrão industrial, e confirmam a importância da participação dos atores locais na constituição de alternativas de desenvolvimento territorial.

Todo esse processo [...] representa um embrião de um modelo de governança participativa, governança regional [...] que bota os conflitos na mesa. Os conflitos que a partir de um processo participativo se vão negociando para criar pequenas vitórias, pequenos consensos em torno de projetos concretos. Acho que esse é o grande avanço do modelo do ABC paulista. O de tentar avançar de maneira flexível, desburocratizada, em torno das grandes prioridades da reestruturação socioeconômica (Ex-secretário de Desenvolvimento e Ação Regional da Prefeitura de Santo André, no AB̉C, São Paulo, 2005).

Para Pires e Neder (2005), o formato multissetorial e interinstitucional da Câmara Regional permite uma atuação com as características de "um conselho de desenvolvimento regional” e, em seus anos de existência,

tem demonstrando a capacidade de se erigir como alternativa virtuosa às tendências de desterritorialização da globalização, seja para a reestruturação da região do $\mathrm{ABC}$ paulista, seja para a construção de novas relações sociais e novos modelos de sociabilidade territorial (Pires e Neder 2005)

Alguns dados sobre os anos 2000 na região do ABC podem evidenciar o lado positivo das articulações político-institucionais da década anterior. É o caso, por exemplo, do surgimento de novos arranjos produtivos locais (Polos de Plástico e de Cosméticos) e da retomada dos níveis de produção e da atividade econômica em geral em setores tradicionais como o metalúrgico e o químico. Houve também redução do fechamento de fábricas e da transferência de produção para outras localidades. Os investimentos anunciados na totalidade dos setores alcançaram cerca de US\$ 3,9 bi- lhões, entre 2001 e 2004 (estimativas da Prefeitura de Santo André). A participação da Indústria no valor adicionado da Região evoluiu de 53,7\% para 61,9\% em 2003 (IBGE/SEADE). A participação do ABC no total da arrecadação de ICMS no Estado de São Paulo voltou a elevar-se a partir de 2001 (Secretaria da Fazenda do Estado de São Paulo). O emprego formal subiu cerca de 35\%, entre 1999 e 2005, e em 16\%, no caso específico do setor industrial (RAIS-CAGED). A taxa de desemprego caiu do patamar de 21\% em 1999 para 16\% em 2005 (PED/SEADE/DIEESE).

A viabilidade de todo esse processo de renovação institucional - uma mobilização coletiva para reverter o quadro de crise econômica que atingia as atividades industriais e a região do $\mathrm{ABC}$ teve a participação decisiva dos sindicatos, em particular do sindicato dos metalúrgicos. Desde a experiência da Câmara Setorial da Indústria Automobilística em 1992, o sindicato dos metalúrgicos tem desempenhado um papel fundamental de formulador, negociador, coordenador, enfim, indutor de políticas públicas, voltadas para o desenvolvimento regional.

Algumas ações associam diretamente o sindicato dos metalúrgicos do ABC com a elaboração de políticas industriais e regionais que almejavam o crescimento industrial, a geração de emprego, a distribuição da renda e a melhoria das condições de vida e de trabalho. Isso ficou mais explícito com a publicação, em novembro de 1995, do documento "Rumos do ABC: a economia do ABC na visão dos metalúrgicos”, elaborado pela subseção do DIEESE local, que apresentava um diagnóstico sobre as dificuldades da economia local e sugeria diretrizes para uma política de desenvolvimento da região.

No âmbito do sindicalismo, a ação das entidades do ABC (seja metalúrgico, químico ou bancário) já representava uma vanguarda, ao incluir, nas suas preocupações, as questões sociais que se mostravam mais candentes com a crise econômica regional. A novidade desse processo está na inclusão da "economia regional” e das "políticas regionais" como temas importantes da pauta sindical. 
O sindicato ao se preocupar com outras questões referentes aos trabalhadores na sociedade [...] enfatizava mais as questões sociais, enfim questão da educação, analfabetismo, transporte, da educação, segurança, habitação etc. Só a partir dos meados anos 1990, [...] os sindicatos passam atuar na esfera da economia, quer dizer, discutir [...] como é que você vai fazer investimento ou, para onde vai o investimento... (Diretor do Sindicato dos Químicos do ABC - 2005).

A década de 1990, portanto, inaugura novas práticas sindicais em função das estratégias impostas pelas mudanças no processo produtivo e nas relações de trabalho. E abre a oportunidade para outro tipo de engajamento político, para além do espaço fabril, utilizando seu acúmulo político de classe para atuar em outros espaços institucionais marcados por outra lógica de interesses e de disputa de poder. Evidentemente, o contexto de crise econômica costuma aproximar atores políticos com interesses divergentes, mas é possível considerar que a ampliação do debate econômico no espaço público, com a participação de organismos ligados aos trabalhadores, pode representar a incorporação de práticas democráticas de debate sobre interesses mais amplos da sociedade que até aquele momento pareciam inexistir.

\section{A CRISE DO FINAL DA DÉCADA DE 2000}

A participação sindical em processos de discussão pública sobre estratégias de desenvolvimento regional, ao longo dos anos 2000, ganhou um grande estímulo com as mudanças políticas em âmbito nacional e local, ocorridas a partir das eleições presidenciais de 2002, com a escolha de Lula para o mais alto posto. As instâncias institucionais, articuladas na esfera municipal e regional na década de 1990, passaram a ter mais interlocução na esfera nacional em relação à política econômica e social. Alguns canais de contato com as instâncias de poder federal se desobstruíram, e o compromisso do presidente da República com o ABC viabilizou um apoio político para iniciativas de desenvolvimento regional. E, mais recentemente, o Partido dos Trabalhadores retomou o poder administrativo de alguns dos municípios da região do $\mathrm{ABC}$, principalmente com a eleição de Luiz Marinho, sindica- lista do ABC, metalúrgico, para a prefeitura de São Bernardo do Campo em 2008.

A crise econômica e financeira do segundo semestre de 2008 foi novamente severa com o ABC, o que obrigou os sindicatos a reativarem iniciativas de caráter público e coletivo, de modo a reagir o mais rápido possível ao crescimento do desemprego e à redução das atividades fabris. A tarefa de reunir esforços transformou os sindicatos em líderes de uma cruzada em busca de alternativas e de soluções, principalmente pela experiência acumulada na década anterior, mas também pela maior facilidade de comunicação com outras instâncias da administração pública. O protagonismo sindical nesse processo de coordenação de atores sinaliza um acúmulo especifico de recursos políticos que talvez só possa ser encontrado no $\mathrm{ABC}$, devido ao seu legado histórico de lutas e organização operária.

Um bom exemplo disso foi o engajamento explicitado nas teses para discussão do VI Congresso dos Metalúrgicos do ABC (Construindo um Brasil justo e democrático: emprego e trabalho decente), ocorrido em maio de 2009. Os trechos selecionados abaixo são uma pequena amostra dessa nova abordagem, a começar pela posição de cobrança de responsabilidade social das empresas. Diz o documento:

... a empresa é, por sua natureza, um empreendimento de caráter social. Desde a sua origem, ela estabelece relações com a sociedade. Esta relação é mediada pelo poder local, de quem geralmente recebe incentivos e subsídios, pela população que consome seus produtos e, de forma especial, pelos trabalhadores que asseguram, através do seu trabalho, o pleno funcionamento e o êxito do empreendimento, seja ele voltado para a produção de bens ou de serviços. [...] Para o sindicato, uma empresa passa a ter responsabilidade social quando incorpora em seu projeto e em suas práticas gerenciais temas da agenda do trabalho decente, como a valorização do diálogo, o respeito aos direitos sindicais e trabalhistas, o combate à discriminação racial, a promoção da igualdade de gênero nas relações de trabalho, a valorização do jovem e do deficiente. (Construindo um Brasil... 2009, p.26).

Sobre a participação dos atores regionais no debate sobre o desemprego, desencadeado pelas mudanças das duas últimas décadas, avalia o documento sindical que: 
Os atores regionais, entre eles os sindicatos, devem colocar em debate o próprio modelo de desenvolvimento que se quer para a região, cujos elementos básicos devem ressaltar: aquele que, primeiro combina crescimento econômico com inclusão social e proteção ao meio ambiente; segundo, que promove uma nova cultura empresarial, baseada na democratização das relações capital-trabalho e na responsabilidade social das empresas; terceiro, que estimula formas inovadoras de mobilização dos recursos econômicos através de redes de pequenas empresas, cuja sustentabilidade (social, técnica e institucional) é assegurada a partir dos efeitos sistêmicos (aglomeração e proximidade) proporcionados pelos territórios em que as redes operam. (Construindo um Brasil... 2009, p.42).

No que diz respeito ao tema específico do que se convencionou chamar no ABC de "regionalidade", o caderno de teses formula uma posição de articulação e negociação de soluções entre diversos representantes da sociedade local:

Entendemos regionalidade como a formação social que surge da articulação de esforços conjuntos de autoridades públicas, de representantes dos trabalhadores, de representantes dos empresários e de outras organizações da sociedade civil, no espaço da região que pode ser geográfico, administrativo, econômico, político e cultural (Construindo um Brasil... 2009, p.48).

A diretoria eleita do sindicato dos metalúrgicos do ABC reafirma, a todo instante, seu compromisso com esse tipo de avaliação política, sempre associada à questão da criação e manutenção de empregos. Tal é o caso de diversas manifestações do seu presidente.

O mundo em sua desafiadora transformação nos obriga a olhar para o futuro, identificar os obstáculos e trabalhar para superá-los desde já. Para cumprir essa tarefa, é fundamental consolidar e fortalecer a consciência de pensar o ABC de forma regional. É justamente nessa regionalidade que está o caminho mais curto para melhorar a qualidade de vida da população do Grande ABC. (Regionalidade também é pauta sindical, Sérgio Nobre - Presidente do Sindicato dos Metalúrgicos do ABC. Jornal ABCD Maior, 14 out. 2008).

Uma das iniciativas de caráter público mais significativas, organizada como reação à crise dos anos 2000 e capitaneada pelos sindicatos do ABC, foi a convocação do seminário "ABC do diálogo e do desenvolvimento", realizado em março de 2009. Desse evento, que reuniu dirigentes políticos dos níveis federal, estadual e municipal, dirigentes do empresariado e dirigentes sindicais, saiu uma carta de compromisso e sugestões para enfrentar as consequências da crise sobre a região. Segundo esse documento:

Todos os consensos resultantes das discussões realizadas nos grupos de trabalho [...] comporão material de trabalho para a reinstalação imediata da Câmara Regional do Grande ABC, que será o fórum de articulação para a consolidação e implementação das propostas [...]

O Grande ABC afirma que a crise será superada com a valorização da negociação, do trabalho, da produção, das pessoas e da cidadania, tendo como valores fundamentais a pluralidade, o respeito à pessoa humana e a democracia. ${ }^{6}$ (Agência de Desenvolvimento do Grande ABC, 13 mar. 2009).

A proposta de reativar a Câmara Regional do ABC recupera a experiência institucional bem sucedida e consolidada durante a crise dos anos 1990. De qualquer forma, a participação ativa das lideranças sindicais nesse processo chama a atenção. Comentando os resultados do seminário, o presidente do sindicato dos metalúrgicos reflete sobre o papel da entidade sindical:

Hoje, por exemplo, temos uma reunião na CUT ABC para discutir o papel dos sindicatos nesse processo de negociação, que será permanente, e amanhã a visita será [à] Associação Comercial de Santo André. Em seguida, vamos levar os resultados do seminário aos poderes públicos. Primeiro para o Consórcio de Prefeitos, depois para o governo do Estado e, por último, ao governo federal. Mas isso leva tempo... A gente sabia que o seminário não apontaria uma saída imediata

Assinam a Carta: Agência de Desenvolvimento Econômico do Grande ABC; Consórcio Intermunicipal Grande ABC; Sindicato dos Metalúrgicos do ABC; Prefeitura de Santo André; Prefeitura de São Bernardo do Campo; Prefeitura de São Caetano do Sul; Prefeitura de Diadema; Prefeitura de Mauá; Prefeitura de Ribeirão Pires; Prefeitura de Rio Grande da Serra; ACISA - Associação Comercial Industrial de Santo André; ACISBEC - Associação Comercial e Industrial de São Bernardo do Campo ACISCS - Associação Comercial e Industrial de São Caetano do Sul; ACE Diadema - Associação Comercial e Empresarial de Diadema; ACIAM - Associação Comercial e Empresarial de Mauá; ACIARP - Associação Comercial, Industrial e Agrícola de Ribeirão Pires; ACIARGS Associação Comercial, Industrial e Agrícola de Rio Grande da Serra; CIESP REGIONAIS ABCD; Sindicatos dos Químicos do ABC; Sindicato dos Bancários do ABC SindusCon-ABC Regional do Sindicato da Indústria da Construção Civil do Estado de São Paulo; Sindicato dos Trabalhadores nas Indústrias Metalúrgicas, Mecânicas e de Material Elétrico de Santo André e Mauá; Sindicato dos Trabalhadores nas Indústrias Metalúrgica, Mecânicas de Material Elétrico e Eletrônico, Siderúrgicas, Veículos e de Auto Peças de São Caetano do Sul. 
para a crise. Seu grande mérito foi juntar atores econômicos e políticos em torno de uma agenda de negociação. A maior parte das propostas apresentadas depende de ações do setor público e esse é o foco da Câmara Regional. Temos a chance de uma participação efetiva, não só para discutir como superar a crise, mas também discutir como é possível melhorar o ABC. (Fonte: Próxima etapa é refazer a Câmara Regional do ABC, afirma Sérgio Nobre, Sindicato dos Metalúrgicos do $A B C, 17$ mar., 2009).

A reação dos sindicatos do $\mathrm{ABC}$ e, em particular, do sindicato dos metalúrgicos, à crise econômica de 2008 demonstra a capacidade acumulada de atuação política e institucional construída ao longo dos anos 1990 e 2000. E essa reação articulada regionalmente tem tido resultados concretos. A região do Grande $\mathrm{ABC}$ foi responsável pelo acréscimo de mais de cinco mil novos postos de trabalho no mês de agosto de 2009, e algumas de suas cidades, como São Bernardo, Santo André e São Caetano, figuraram entre as que mais empregaram no país nesse mês.

O ABCD criou 5.256 postos de trabalho no mês passado e reverteu a tendência de queda do emprego criada a partir da crise financeira mundial. Os dados do Caged (Cadastro Geral de Empregados e Desempregados), divulgados nesta quarta-feira (16/09) pelo Ministério do Trabalho, representam um salto na criação de emprego na Região, já que em julho o resultado ainda era negativo, com a perda de 18 postos de trabalho na Região. Agosto também marcou a recuperação do emprego nas indústrias de transformação da Região. No mês, a atividade econômica criou 1.198 vagas de trabalho no ABCD. Em julho, o setor havia fechado 414 postos de trabalho na Região. Vale destacar que as principais atividades econômicas apresentaram [resultados positivos] na geração de emprego no ABCD no mês passado. Enquanto o setor de serviços teve saldo de 2.594 vagas criadas, o comércio gerou 961 postos de trabalho e a construção civil 538 (Criação de emprego dispara no ABCD em agosto, Jornal ABCD Maior, 16 set. 2009).

Essas informações podem ser vistas como sinais de melhora da situação econômica e do emprego na região no início de segundo semestre de 2009. Representam, a nosso ver, uma combinação entre ações do governo federal e a forma como o Grande ABC articulou a seu favor os setores públicos e privados, as classes trabalhadoras e o setor empresarial, o setor público nos âmbitos federal, estadual e municipal. Do ponto de vista re- gional, essa dinâmica não teria sido possível, sem a capacidade político-social do sindicato dos metalúrgicos do $\mathrm{ABC}$ de funcionar - junto à sociedade civil e ao poder público - como organizador e formulador de políticas voltadas para o desenvolvimento regional.

\section{CONCLUSÃO}

A participação dos sindicatos do $\mathrm{ABC}$ e os recursos políticos por eles acionados na formulação de novas estratégias regionais de desenvolvimento, especialmente em contextos de crise econômica, são um bom exemplo para o debate sobre novas pautas e novas dificuldades que desafiam as organizações dos trabalhadores nos dias atuais. Entre esses recursos está a história dos sindicatos formados no contexto do processo de industrialização brasileiro e no acúmulo de força política associado à militância dentro e fora dos locais de trabalho. Em ambas as crises que atingiram a região (anos 1990 e anos 2000), a ação sindical foi proativa, no sentido de buscar alternativas para manter e criar empregos e viabilizar atividades econômicas regionais. Sua atuação política, para além das atividades corporativas, e o embate de interesses em outras instâncias públicas parecem indicar uma consolidação de práticas de articulação, iniciadas e experimentadas nos anos 1990, que retomaram o cenário político e se refizeram em função das necessidades colocadas para todos os atores instalados naquele território novamente em 2008 e 2009.

Para terminar, queremos ressaltar alguns aspectos desse debate para futuras discussões.

Um primeiro aspecto se refere à conversão do capital político acumulado nas lutas sindicais em outro tipo de recurso político, acionado em outras esferas de interesse, relacionadas a questões de coordenação institucional fora do espaço da produção. A experiência dos últimos vinte anos no ABC reforça a percepção sobre a importância dos sindicatos nas experiências de inovação institucional que envolvem os atores sociais de localidades e regiões em crise. Nota-se, no caso 
estudado, que as articulações nesse nível não anularam as diferenças de classe presentes nos universos fabris, assim como não reduziram os conflitos associados às questões salariais e às condições de trabalho. A reconstituição das ações do sindicato dos metalúrgicos do ABC, por exemplo, demonstra sua atuação de caráter mais propositivo, tanto no sentido de negociar com as empresas o impacto da reestruturação sobre os empregos e as relações de trabalho, como na busca de novos espaços públicos de discussão sobre os destinos regionais, incluindo a promoção do cooperativismo e a preservação da renda. Em 2009, a realização do seminário "ABC do diálogo e do desenvolvimento" parece ter sido um passo adiante no amadurecimento e na institucionalização das estratégias de participação em âmbito regional e local. Isso não significa desconsiderar as enormes dificuldades, limitações e conflitos que estão presentes em iniciativas desse tipo, que envolvem atores com inserções sociais diferenciadas e são marcadas por uma complexa disputa de interesses e poder. No entanto, a ação sindical de 2009 confirma a incorporação, no conjunto das reivindicações trabalhistas, das questões econômicas regionais que interferem na vida cotidiana dos que vivem do trabalho e, ao mesmo tempo, revela uma particular combinação política de práticas que usam o acesso à administração pública como estratégia para obter avanços nas conquistas sociais.

Um segundo aspecto confirma essa disputa de interesses e poder. Refere-se aos percalços do relacionamento das empresas multinacionais com as pequenas e médias empresas no contexto regional e à divergência de interesses e perspectivas, principalmente nos momentos de crise. A mobilização política pela revitalização industrial do ABC, nos anos 1990, colocou em xeque as diretrizes de planejamento estabelecidas pelas empresas cujas sedes estavam localizadas fora do Brasil e que habitualmente não se sentiam na obrigação de se envolver em negociações e planos de desenvolvimento a partir do espaço regional ou local. As articulações políticas, refundadas na crise dos anos 2000, criaram situações de constrangimento para essas empresas, ao exigir contrapartidas econômicas e sociais e a participação efetiva nas instâncias locais de debate sobre questões regionais. Por outro lado, as crises dos últimos vinte anos impulsionaram um engajamento efetivo das pequenas e médias empresas no novo processo institucional e na formulação de um plano regional por cadeia produtiva para potencializar vantagens competitivas e valorizar os acúmulos de conhecimento e práticas que sejam próprias da região.

Um terceiro aspecto refere-se à ação do Estado e dos órgãos da administração pública, que ganham outra dimensão nos momentos de crise regional e que são acionados pelo seu poder de arregimentação e implementação de políticas públicas no processo de coordenação dessas novas experiências institucionais. No caso do ABC, os agentes do setor público, embora de origens políticas diferentes, buscaram e, de certa forma, foram bem sucedidos, na elaboração de estratégias de internalização de serviços industriais avançados, tais como a logística, o processamento de dados, a engenharia de produtos, o marketing, entre outros. O balanço dessa experiência demonstra o avanço em algumas pautas e diretrizes voltadas para o aprofundamento de políticas de revitalização local que tiveram participação importante dos órgãos públicos. A presença de um sindicalista metalúrgico na prefeitura de São Bernardo do Campo (eleito em 2008) fez crescer o discurso sobre a necessidade de integrar, de forma coordenada, as demandas da indústria do ABC com os programas, pesquisas e ações das escolas técnicas, universidades e centros de Pesquisa \& Desenvolvimento na região. E as políticas de incentivo às inovações de produtos e processos, na região, passaram a ser vistas como promotoras de ganhos de competitividade, fundamentais à preservação do parque industrial local e à manutenção das conquistas trabalhistas.

Por fim, este caso traz mais elementos para um debate sobre estratégias de desenvolvimento local em contexto de globalização, sobre a refundação de espaços territoriais a partir de recursos específicos constituídos ao longo do tem- 
po, sobre a constituição de novos espaços institucionais nos quais atores sociais são chamados a repensar práticas de negociação política e de formular propostas de desenvolvimento a partir de espaços públicos. E ainda sobre o papel dos organismos de representação dos trabalhadores, que utilizam seu acúmulo de relações políticas no exercício das novas práticas democráticas de discussão sobre modelos de desenvolvimento e na busca de alternativas com vistas a garantir melhores condições de trabalho e de vida para seus representados e para a população em geral.

(Recebido para publicação em novembro de 2009) (Aceito em maio de 2010)

\section{REFERÊNCIAS}

ABRUCIO, Fernando; SOARES, Márcia M. Redes federativas no Brasil: cooperação intermunicipal no Grande ABC. São Paulo: Fundação Konrad Adenauer, 2001 (Série pesquisas, 24).

ALBUQUERQUE, F. La iniciativa de desarrollo regional del "Gran ABC", São Paulo (Brasil). São Paulo: Agência de Desenvolvimento Econômico do Grande ABC e Banco Interamericano de Desenvolvimento, 2001. mimeo.

ANDERSON, Patrícia. Câmaras setoriais: histórico e acordos firmados, 1991/95. Texto para Discussão, Rio de Janeiro, IPEA, n.667, 1999.

ARBIX, Glauco. Guerra fiscal, espaço público e indústria automobilística no Brasil. In: CARDOSO, Adalberto; COVARRUBIAS, Alex. (Org.) A indústria automobilística nas Américas - a reconfiguração estratégica e social dos atores produtivos. Belo Horizonte: Editora da UFMG, 2006. p.35-61.

. Uma aposta no futuro: os primeiros anos da câmara setorial da indústria automobilística. São Paulo: Scritta, 1996.

A câmara banida. In: ; ZILBOVICIUS,

Mauro. (Org.) De JK a FHC: a reinvençẫo dos carros. São Paulo: Scritta, 1997. p.471-502.

BONIFACE, D. Post-statist development iniciatives in Greater 'ABC' São Paulo: a case study in innovation. 2001. Tese (Doutorado em Ciência Política), University of Illinois. Urbana-Champaign. 2001.

BRESCIANI, Luís Paulo. Instituições, agenda regional, desenvolvimento econômico e política sindical no Grande $A B C$ : os desafios do equilíbrio entre (macro) esfera institucional regional e a (micro) esfera cotidiana produtiva. Caxambu: Anpocs, 2004.

; BENITES FILHO, Flávio A. Negociações tripartites na Itália e no Brasil: o acordo nacional e as câmaras setoriais. São Paulo: LTr, 1995.

CÂMARA REGIONAL DO GRANDE ABC. A região encontra soluções. Santo André-SP: 2000a.
Planejamento Regional Estratégico. Santo André,SP: $2000 \mathrm{~b}$.

CAMARGO, Zeíra M. O Sindicato dos Metalúrgicos do $A B C$ e as acões regionais na década de 90. Dissertação (Mestrado em Administração) - Centro Universitário Municipal de São Caetano do Sul - IMES. 2003.

CARDOSO, Adalberto M. A nova face da indústria automobilística brasileira ou a tese da convergência revisitada. In: $\quad$; COVARRUBIAS, Alex. (Org.) A indústria automobilística nas Américas - a reconfiguração estratégica e social dos atores produtivos. Belo Horizonte: Editora da UFMG, 2006. p.79-112.

Rompendo o círculo de ferro: impactos do acordo das montadoras nas relações de trabalho no setor automotivo brasileiro. In: OLIVEIRA, Francisco de; COMIN, Álvaro. (Org.) Os cavaleiros do antiapocalipse: trabalho e política na indústria automobilística. São Paulo: Cebrap/Entrelinhas, 1999a.

Sindicatos, trabalhadores e a coqueluche neoliberal. Rio de Janeiro: FGV Editora, 1999b.

. COMIN, Alvaro A. Câmaras Setoriais, modernização produtiva e democratização nas relações entre capital e trabalho no Brasil. In: CASTRO, Nadya de Araújo. (Org.) A máquina e o equilibrista. São Paulo: Paz e Terra, 1995.

CARTA DO ABC, 25 ago. 2009.

CASTELLS, Manuel. A sociedade em rede. São Paulo: Paz e Terra, 1999. v.1.

COCCO, G.; GALVÃO, A. P.; SILVA, M. C. P. Desenvolvimento local e espaço público na Terceira Itália. In:

URANI, A; GALVÅO, A. (Org.) Empresários e empregos nos novos territórios produtivos: o caso da Terceira Itália. Rio de Janeiro: DP\&A, 1999.

CONCEIÇÃO, Jefferson José da. Quando o apito da fábrica silencia - sindicatos, empresas e poder público diante do fechamento de industrias e da eliminação de empregos na região do $A B C$. São Paulo: ABCD Maior, 2008.

As fábricas do $A B C$ no olho do furacão: a indústria de autopeças e a reestruturação da cadeia de produção automotiva nos anos 90. 2001. Dissertação (Mestrado em Administração) - Centro Universitário Municipal de São Caetano do Sul - IMES. São Paulo, 2001.

CONSÓRCIO INTERMUNICIPAL DO GRANDE ABC. Comunidade Cidadã. Disponível em: http:// www.consorcioabc.org.br/comunidade.htm, 2006.

CONSTRUINDO um Brasil justo e democrático: emprego e trabalho decente. In: CONGRESSO DOS METALÚRGICOS DO ABC.6, São Bernardo do Campo, 2009. Caderno de Teses... São Bernardo do Campo: Sindicato dos Metalúrgicos do ABC, 2009. p.26,42,48

DANIEL, Celso. Gestão compartilhada, limites e possibilidades: a experiência do Grande ABC. In: CONSÓRCIO... uma forma de cooperação intermunicipal. São Paulo: Fundação Prefeito Faria Lima/Cepam, 2001a.

Uma experiência de desenvolvimento econômico local: a Câmara Regional do Grande ABC. In: GUIMARÃES, Nadya A.; MARTIN, Scott. (Org.) Competitividade e desenvolvimento: atores e instituições locais. São Paulo: SENAC, 2001b. p.449-468.

Sindicatos e desemprego no ABC. Diário do Gran$\overline{\text { de } A B C}$, Santo André, 23 ago., Cad.1, 4, 1995.

Uma estratégia econômica para o Grande $A B C$. Brasília: Câmara dos Deputados, 1996.

; SOMEKH, Nadia. Novas estratégias de ação regional: a experiência recente da Câmara do Grande ABC. In: ENCONTRO NACIONAL DA ANPUR, 1999, Porto Alegre. Anais... Porto Alegre, 1999. 
DINIZ, Eli. Articulação dos atores na implantação da política industrial: a experiência das câmaras setoriais retrocesso ou avanco na transicão para um novo modelo? Campinas: IE-UNICAMP / IEI-UFRJ / FDC / FUNCEXNota Técnica do Estudo de Competitividade da Indústria Brasileira, 1993.

FRANCO, Gustavo. A lavagem de um subsídio. Folha de São Paulo, 22 abr. 1993. Cad. dinheiro, 2.

Maravilhas do acordo automobilístico. Folha de São Paulo, 14 jul. 1992, Cad. dinheiro, 2.

GOMES, Edgar da N. Planejamento econômico local, desenvolvimento e participação social: a experiência das cidades do Grande $A B C$ Paulista. 1999. Dissertação (Mestrado em Economia) - PUC-SP, 1999.

GUIMARÃES, Nadya; MARTIN, Scott. Descentralização, equidade e desenvolvimento: atores e instituicões locais. In: ; MARTIN, S. (Org.) Competitividade e desenvolvimento - atores e instituições locais. São Paulo: Editora Senac, 2001. p.11-29.

; COMIN, A.; LEITE, M.P. Por um jogo de soma positiva: conciliando competitividade e proteção ao emprego em experiências inovadoras de negociação no Brasil. In: ; MARTIN, S. (Org.) Competitividade e desenvolvimento - atores e instituições locais. São Paulo: Editora Senac, 2001. p.417-448.

HORTA, Celso A O braço "direito" do Grande ABC: um estudo de caso do Diário do Grande ABC e sua inserção na regionalidade e nos conflitos das relações de trabalho. 2003 Dissertação (Mestrado em Administração) - Centro Universitário Municipal de São Caetano do Sul - IMES, 2003.

KLINK, Jeroen. Secretaria de Relações Internacionais e Captação de Recursos da Prefeitura de Santo André: novos desafios através de uma visão estratégica. Global. Rio de Janeiro, n.0, 2003.

A cidade-região: regionalismo e reestruturação no Grande ABC paulista. Rio de Janeiro: DP\&A, 2001.

O novo regionalismo: o caso da região do Grande ABC. 2000. Tese (Doutorado em Arquitetura e Urbanismo) - Universidade de São Paulo, 2000.

LEITE, Márcia de P. Nova estrutura industrial e trabalho: a experiência da Câmara Regional do Grande ABC no Brasil. Campinas: DECISA/UNICAMP, 1999. mimeo.

ARINHO, Luiz. A fábrica além do prédio. Folha de São Paulo. 21 fev. 2001.

MEYER-STAMER, Jörg. Estratégias de desenvolvimento local e regional: clusters, política de localização e competitividade sistêmica. Policy Paper: Friedrich Ebert Stiftung - ILDES, São Paulo, n.28, set. 2001.

OLIVEIRA, Francisco. O acordo das montadoras: quanto melhor, melhor, Novos Estudos CEBRAP, São Paulo, n.36, 1993. ros do antiapocalipse: o acordo das montadoras. São Paulo: CEBRAP, 1992. (Projeto de pesquisa)

PETROLLI, Valdenízio. Diário do Grande ABC: a construcão de um jornal regional. 2000. Tese (Doutorado em Teoria e Ensino da Comunicação) - Universidade Metodista de São Paulo - UMESP. São Bernardo do Campo,SP: 2000

PIRES, Élson; VERDI, Adriana R. As dinâmicas territoriais locais na globalização: aspectos conceituais e metodológicos, Revista Geosul, São Paulo, 2007.

; NEDER, R.T. A governança territorial no Brasil: as instituições, os fatos e os mitos. In: SEMINARIO IN TERNACIONAL - Analyse des Changements Institutionnels: caractérisation, méthodes, théories, acteurs. La Rochelle, Fr.: 2005.
PECQUEUR, Bernard. O desenvolvimento territorial: uma nova abordagem dos processos de desenvolvimento para as economias do Sul. Raízes, Campina Grande, UFCG, v.24, n.1/2, p.10-22, jan./dez., 2005.

RAMALHO, J.R.; RODRIGUES, I.J.; CONCEIÇÃO, J. J. Reestruturação industrial, sindicato e território - alternativas políticas em momentos de crise na região do $\mathrm{ABC}$ em São Paulo - Brasil. Revista Crítica de Ciências Sociais, Coimbra, Universidade de Coimbra, n.85, 2009.

REIS, Regina C. dos. Articulação política regional: a experiência do Grande ABC, 1990-2005. 2005. Tese (Doutorado em Ciências Sociais) - PUC-SP, 2005.

REVISTA ABC do diálogo e do desenvolvimento - a região unida para enfrentar a crise. São Bernardo do Campo,SP: Agência de Desenvolvimento Econômico do Grande ABC/ Imprensa do Sindicato dos Metalúrgicos do ABC, mar. 2009.

RODRIGUES, I. J.; RAMALHO, J.R. Trabalho e Sindicato em antigos e novos territórios produtivos: comparações entre o ABC paulista e o Sul fluminense. São Paulo: Annablume, 2007. 364 p.

Sindicalismo e política - a trajetória da CUT. São Paulo: Scritta/Fapesp, 1997

SENGENBERGER, W.; PIKE, F. Distritos industriais e recuperação econômica local: questões de pesquisa e de política. In: COCCO, G.; URANI, A.; GALVÃO, A. (Org.) Empresários e empregos nos novos territórios produtivos: o caso da Terceira Itália. Rio de Janeiro: DP\&A, 1999.

SILVA, Leonardo Mello. A generalização difícil: a vida breve da Câmara Setorial do complexo químico seguida do estudo de seus impactos em duas grandes empresas do ramo em São Paulo. 1997. Tese (Doutorado) - Universidade de São Paulo.1997.

SCOTT, Allen. Revitalização industrial nos municípios do ABC, São Paulo. Análise diagnóstica e recomendações estratégicas para uma nova economia e um novo regionalismo. São Paulo: Agência de Desenvolvimento Econômico do ABC/Banco Interamericano de Desenvolvimento, 1999. (Relatório de pesquisa)

STORPER, Michael. Las economias regionales como activos relacionales, Cadernos IPPUR, Rio de Janeiro, v.13, n.2, ago./dez., 1999. 


\section{TRADE UNIONS, ECONOMIC CRISIS AND REGIO- NAL STRATEGIES - new dimensions of political participation in the Paulistan ABC}

\author{
José Ricardo Ramalho \\ Iram Jacome Rodrigues
}

The proposal of this paper is to discuss, from the case of São Paulo ABC, the strategies unions created in contexts of economic crisis, and analyze the mechanisms of mobilization triggered to propose political-institutional alternatives in a regional framework, in order to protect and encourage the creation of jobs and to address the social effects of layoffs of workers. The main hypothesis is that the action of trade unions with a tradition of labor struggle, institutional density and national and regional political accumulation, with active channels for dialogue with national, state and municipal governments and with strength to raise their categories, eventually play a decisive role, and somehow an innovative one in designing new institutional mechanisms to discuss political strategies for dealing with the difficulties imposed on localities and regions, starting to exert their influence in new conceptions built on situations of regional economic crisis.

KEYworDS: economic crisis, union, productive territories, region of ABC-Brazil.

\section{SYNDICAT, CRISE ÉCONOMIQUE ET STRATÉGIES \\ RÉGIONALES - nouvelles dimensions de la participation politique dans l'ABC de Sao Paulo}

\author{
José Ricardo Ramalho \\ Iram Jácome Rodrigues
}

Le propos de cet article est de discuter, à partir du cas de l'ABC de Sao Paulo, les stratégies syndicales créées dans des contextes de crise économique et d'analyser les mécanismes de mobilisation mis en œuvre pour proposer des alternatives politiques et institutionnelles dans un cadre régional afin de protéger et d'encourager la création d'emplois et d'affronter les effets sociaux des démissions de travailleurs. L'hypothèse principale est que l'action des syndicats, ayant pour tradition de lutter pour défendre les droits du travail, ayant une densité institutionnelle et une accumulation politique régionale et nationale, disposant de canaux de communication avec les gouvernements municipaux, régionaux et nationaux et ayant un pouvoir de mobilisation de leurs catégories, finissent par jouer un rôle décisif et en quelque sorte innovateur dans la définition de nouveaux mécanismes institutionnels capables de discuter les stratégies politiques pour faire face aux difficultés que rencontrent les régions et les localités. Ils finissent par avoir une influence sur les nouvelles conceptions élaborées dans des situations de crise économique régionale.

Mots-CLÉs: crise économique, syndicat, territoires productifs, région de l'ABC-Brésil.

José Ricardo Ramalho - Doutor em Ciência Política pela Universidade de São Paulo. Professor Titular de Sociologia do Programa de Pós-Graduação em Sociologia e Antropologia da Universidade Federal do Rio Janeiro (UFRJ). Autor, entre outros, de Estado Patrão e Luta Operária - o caso FNM (Rio de Janeiro: Paz e Terra, 1989) e da coletânea Trabalho e Sindicato em antigos e novos territórios produtivos, com Iram Jácome Rodrigues (São Paulo: Annablume, 2007).

Iram Jácome Rodrigues - Doutor em Sociologia pela Universidade de São Paulo. Professor do Departamento de Economia e do Programa de Pós-Graduação em Sociologia da Universidade de São Paulo (USP). Autor, entre outros, de Sindicalismo e Política - a trajetória da CUT (São Paulo: Scritta/Fapesp, 1997) e da coletânea Trabalho e Sindicato em antigos e novos territórios produtivos, com José Ricardo Ramalho (São Paulo: Annablume, 2007). 